\title{
GOMMENTARY
}

— How Do We Teach? -

\section{Competency-Based Education in Family Medicine Residency Education}

John Saultz, MD

(Fam Med. 2021;53(7):590-2.)

doi: 10.22454/FamMed.2021.816448

Published Online First May 17, 2021

C ompetency-based medical education (CBME) has become the dominant paradigm in medical schools and residency programs across the Unites States. ${ }^{1}$ The model describes a roadmap for designing educational programs and an underlying philosophy for how teaching and learner evaluation should be done. Eric Holmboe, MD, has done a fine job of reviewing the history of CBME and has described many of the struggles it has encountered. ${ }^{2}$ While there is already a rich literature on this topic, much of this work has been published in journals not routinely read by family medicine residency educators. ${ }^{3-9}$ Still, this journal has published two papers examining CBME in family medicine residencies within the past year. ${ }^{10,11}$ And yet we all struggle with how to make the model work in our own programs as each iteration of the Accreditation Council for Graduate Medical Education (ACGME) Family Medicine Program Requirements moves us farther into new territory. Today, the job of a residency teacher requires an in-depth understanding of CBME and a mastery of the new skills it requires of us.

While the focus of this commentary is on residency education, family medicine residencies are dramatically affected by how CBME is being implemented at the undergraduate level. Medical schools have adopted CBME in diverse ways and this has significantly impacted the skill set of new residents arriving for the first year of training. Over the past 2 decades, scores of new allopathic and osteopathic medical schools have opened, ${ }^{12,13}$ often using a highly decentralized model of clinical training that more closely resembles the model of the Caribbean schools. And each has taken its own approach to competency assessment, often placing responsibility for learner evaluation in the hands of inexperienced community physicians. A careful assessment of entering residents has always been important, but this is now more challenging than ever because the skill levels of students seem more heterogeneous than in the past. In some cases, basic skills are more carefully taught and documented in medical school, but it is also true that students arrive with more variability in their levels of clinical experience. This impacts residency education dramatically, often requiring closer resident supervision and more detailed and frequent assessments of resident progress. Some specialties have taken specific steps to address this problem, such as transition to residency boot camps and warm handoffs between the medical school and residency. ${ }^{14}$ While this can be frustrating, it is important to remember why we are doing all this in the first place. Health care in America costs far too much and delivers poor outcomes when compared to other countries. The process of residency education lies at the heart of changing physician performance, and implementing CBME is how we are collectively trying to make things better.

Nevertheless, there are problems with the model itself and with our ability to effectively

From the Oregon Health \& Science University, Department of Family Medicine, Portland, OR. 
implement it in our daily work. The underlying problems with the model include:

1. It is highly dependent on the skills of faculty members to accurately assess learners at the granular level of each residency competency. This, in turn, depends on both the training of the faculty and on the time they have available for this work.

2. It tends to assume that a resident who has achieved every required competency will be both qualified and confident to enter community practice. There is not yet conclusive evidence that this is the case, particularly in a field as broad as family medicine. Our discipline requires astonishing breadth of training compared to narrower fields and it only follows that both competence and confidence are harder to attain and document. Importantly, competence and confidence are not the same thing, and both are essential if we want graduates to conquer their fear of practicing in isolated, low-resource settings. We share this problem with other generalist fields like general surgery and emergency medicine.

3. CBME was introduced to improve the quality and safety of medical practice, but quality and safety are not solely attributes of physician competency. Competent physicians working in dysfunctional systems of care may not be sufficient to deliver measurable system improvement. Certainly, this is why we have a competency domain for systems-based practice, but if the past 20 years have taught us anything, it has shown that physicians no longer control the systems in which we work. This raises the very real question of whether the desired outcomes of CBME can be achieved.

4. CBME requires us to agree what a competent family physician should be trained to do, and our discipline has struggled to come to agreement about this for over 50 years.

In addition to these and other problems with the model itself, there are real problems with its implementation in family medicine residencies. Consider the following:

1. A majority of family medicine programs are in community hospital settings, often where they are the only residency program. Much can be learned about CBME across medical specialties, but these interdisciplinary experiences are less available in family medicine than in any other discipline.
2. While the accurate and reproducible assessment of family medicine resident competency is a challenge for full-time faculty, developing these new faculty skills is even harder when the assessment is done by practicing community physicians. Family medicine residents still work extensively on rotations with physicians in other specialties, and helping such preceptors to develop skills in competency assessment is a huge challenge.

3. CBME places an enormous responsibility on the faculty who conduct competency assessments, and there are at least three reasons to worry about our ability to pull this off. First, competency assessment appears to be much more time consuming than traditional documentation of rotation completion or procedures performed. But faculty have less time today than in the past, and recent changes to the ACGME common program requirements are likely to worsen this problem. ${ }^{15}$ Second, we need a system to accurately assess faculty competency to perform these assessments and such a system does not yet exist. Third, and perhaps most important, there are real conflicts of interest built into the assessment process. The COVID-19 pandemic has clearly demonstrated that the United States desperately needs physicians on the front lines. So the financial and political pressure to get new physicians out the door is substantial. In a worst-case scenario, we risk lowering our educational standards in the interest of expediency even as we try to raise the bar.

CBME is clearly here to stay. As a result, we face a substantial faculty development challenge; all of us should take this very seriously. The first step must be to reexamine the core competencies of family medicine and define the common characteristics we will expect in all future family physicians, and then, we must hold residencies accountable for producing such physicians. CBME was adopted to make health care safer, but it is far from clear that it can accomplish this without much more fundamental change in how health care is funded and delivered in America. It is not a panacea. In fact, it is a complex model that requires fundamental change in how we do the ongoing work of training family physicians. We can complain about this, or we can embrace the challenge of proving whether or not it actually works in the real world. Most of graduate medical education takes place in large 
academic health centers. Family physicians, perhaps more than any other specialty, have always known that such settings are artificial environments. Admittedly, family medicine residencies are also quite different from community practices, but at least they are located in the community and interface with people who are in full-time practice. So, the success or failure of CBME may actually depend on our discipline to demonstrate that it can work in the real world. CBME is not the goal; it is a tool, and the usefulness of tools depends on the skill of those using them.

CORRESPONDENCE: Address correspondence to Dr John Saultz, Oregon Health \& Science University, Department of Family Medicine, 81 S.W. Sam Jackson Park Road, Mail Code FM, Portland, OR 97239-3098. 503-494-7206. saultz@mac.com.

\section{References}

1. Saultz J. Experience Matters. Fam Med. 2021;53(1):7-8. doi:10.22454/FamMed.2021.572008

2. Holmboe ES. Competency-based medical education in family medicine. Fam Med. 2021;53(7):583-589.

3. Mann KV. Theoretical perspectives in medical education: past experience and future possibilities. Med Educ. 2011;45(1):6068. doi:10.1111/j.1365-2923.2010.03757.x

4. Ten Cate O. Competency-based postgraduate medical education: past, present, and future. GMS J Med Educ. 2017;34(5):Doc69.

5. Holmboe ES. Competency-based medical education and the ghost of Kuhn: reflections on the messy and meaningful work of transformation. Acad Med. 2018;93(3):350-353. doi:10.1097/ACM.0000000000001866

6. Holmboe ES. Realizing the promise of competencybased medical education. Acad Med. 2015;90(4):411-413. doi:10.1097/ACM.0000000000000515
7. Williams RG, Dunnington GL, Mellinger JD, Klamen DL. Placing constraints on the use of the ACGME milestones: a commentary on the limitations of global performance ratings. Acad Med. 2015;90(4):404-407. doi:10.1097/ ACM.0000000000000507

8. Schultz K, Griffiths J. Implementing competency-based medical education in a postgraduate family medicine residency training program: a stepwise approach, facilitating factors, and process of steps that would have been helpful. Acad Med. 2016;91(5):685-689. doi:10.1097/ACM.0000000000001066

9. Williams RG, Dunnington GL, Mellinger JD, Klamen DL. Placing constraints on the use of the ACGME milestones: a commentary on the limitations of global performance ratings. Acad Med. 2015;90(4):404-407. doi:10.1097/ ACM.0000000000000507

10. Campbell C, Hendry P, Delva D, Danilovich N, Kitto S. Implementing competency-based medical education in family medicine: a scoping review on residency programs and family practices in Canada and the United States. Fam Med. 2020;52(4):246-254. doi:10.22454/FamMed.2020.594402

11. Danilovich N, Kitto S, Price DW, Campbell C, Hodgson A, Hendry P. Implementing competency-based medical education in family medicine: a narrative review of trends in assessment. Fam Med. 2021;53(1):9-22. doi:10.22454/ FamMed.2021.453158

12. Whitcomb ME. The development of new MD-granting medical schools in the Unites States in the 21st century. Acad Med 2020;95(3):340-343. doi:10.1097/ACM.0000000000003048

13. American Association of Colleges of Osteopathic Medicine. U.S. Colleges of Osteopathic Medicine. https://www.aacom. org/become-a-doctor/u-s-colleges-of-osteopathic-medicine. Accessed February 16, 2021.

14. Murphy B. Pre-residency boot camps prep med school grads for new realities. American Medical Association. https://www. ama-assn.org/residents-students/residency/pre-residencyboot-camps-prep-med-school-grads-new-realities. Published April 4, 2018. Accessed November 22, 2020.

15. Newton WP, Magill M. The impact of the ACGME's June 2019 changes in residency requirement. J Am Board Fam Med. 2020;33(6):1033-1036. doi:10.3122/jabfm.2020.06.200557 